\title{
COMPETÊNCIAS SÃO IMPORTANTES PARA AGENTES DE VIAGEM? UM ESTUDO EXPLORATÓRIO EM AGÊNCIAS DE PORTO ALEGRE
}

\author{
ARE COMPETENCES IMPORTANT FOR TRAVEL AGENTS? AN EXPLORATORY STUDY IN AGENCIES \\ OF PORTO ALEGRE
}

\author{
¿ES IMPORTANTE QUE LOS AGENTES DE VIAJES SEAN COMPETENTES? UN ESTUDIO \\ EXPLORATORIO EN AGENCIAS DE PORTO ALEGRE
}

Thais Bellenzier dos Santos

PUCRS - Pontifícia Universidade Católica do RS Especialista em Gestão Estratégica de Negócios pela PUCRS e Bacharel em Gestão de Turismo e Hotelaria pela PUCRS Porto Alegre/RS, Brasil tbellenzier@gmail.com

Ana Clarissa Matte Zanardo dos Santos

PUCRS - Pontifícia Universidade Católica do RS Professora e Pesquisadora no PPGAd da PUCRS Doutorado e Mestrado em Administração de Empresas pela UNISINOS/RS Porto Alegre/RS, Brasil ana.clarissa@pucrs.br

RESUMO: O presente artigo busca compreender quais são as principais competências necessárias a profissionais atuantes na área de vendas das agências de viagens localizadas em Porto Alegre/RS. Para tanto, realizou-se uma pesquisa de natureza quantitativa, utilizando uma survey para coleta de dados. Dentre as cento e oitenta agências de viagens existentes em Porto Alegre/RS, foram recebidos 69 questionários respondidos. Para analisar os dados foram utilizadas a estatística descritiva, a análise fatorial, a correlação, o teste T e a Anova, conforme a natureza dos dados. Apesar de o construto utilizado na pesquisa apontar três dimensões para analisar as competências - Conhecimentos, Habilidades e Atitudes -, o estudo apontou cinco dimensões: Habilidade, Qualificação Técnica, Conhecimento Tácito, Atitude e Conectividade. Os resultados evidenciaram, também, que a formação do profissional é baseada na escolaridade, mas as suas vivências pessoais tornam cada profissional único. Os resultados apresentados mostram que o fator Habilidade é considerado o mais relevante sob o ponto de vista dos gestores.

PALAVRAS-CHAVE: Competências. Profissional de Vendas. Agências de viagem.

\begin{abstract}
The focus of this study is to understand the main competences necessary for sales professionals of travel agencies in Porto Alegre, in the State of Rio Grande do Sul. A quantitative study was conducted, using a survey to gather data. Of the surveys sent out to the hundred and eighty travel agencies that exist in the city, sixty-nine questionnaires were filled out and returned. The following methods were used to analyze the data: descriptive statistics, factorial analysis, correlation, T-test and Anova, depending on the nature of the data. Even though the research model indicates three dimensions to analyze competences - Knowledge, Ability and Attitudes - this study identified five categories: Ability, Technical Qualification, Tacit Knowledge, Attitude and Connectivity. The results showed that although professional training is based on education, their personal experiences make each professional unique. The results also showed that the factor Ability is considered the most important, in the managers' view.
\end{abstract}

KEYWORDS: Competence. Sales Professional. Travel agencies.

1 A autora agradece o apoio da CAPES. 
RESUMEN: El presente artículo intenta comprender cuáles son las principales competencias necesarias para los profesionales que actúan en el área de ventas de las agencias de viajes ubicadas en Porto Alegre/RS. Para ello se realizó un estudio de naturaleza cuantitativa utilizando una survey para la recolección de datos. Se recibieron 69 cuestionarios respondidos de las ciento ochenta agencias de viajes existentes en Porto Alegre/RS. Para analizar los datos se utilizó la estadística descriptiva, el análisis factorial, la correlación, el test T y la prueba Anova, conforme la naturaleza de los datos. A pesar de que el constructo utilizado en la investigación señala tres dimensiones para analizar las competencias - Conocimientos, Habilidades y Actitudes -, el estudio apuntó cinco dimensiones: Habilidad, Calificación Técnica, Conocimiento Tácito, Actitud y Conectividad. Los resultados también evidenciaron que la formación del profesional se basa en la escolaridad, pero sus vivencias personales hacen que cada profesional sea único. Los resultados presentados muestran que el factor Habilidad es considerado el más relevante desde el punto de vista de los gestores.

PALABRAS CLAVE: Competencias. Profesional de Ventas. Agencias de viajes.

\section{INTRODUÇÃO}

s agências de viagens têm como objetivo a intermediação da
compra e venda de serviços turísticos entre os fornecedores e o
consumidor final. Este serviço vem perdendo espaço para os portais on-line e precisa constantemente encontrar diferenciais no seu atendimento e na oferta de novos produtos. Esta necessidade faz com que muitas agências acabem abrindo mão das operadoras turísticas (fornecedores), sendo necessário elaborar pacotes de viagens diferenciados e inovadores.

A internet mudou a forma como as pessoas consomem o turismo e adquirem viagens: as OTAs (On-line Travel Agency) são responsáveis por este novo panorama. Devido ao grande crescimento dos portais on-line no Brasil, as agências de turismo tradicionais procuram utilizar a internet a seu favor, agregando serviços personalizados ao serviço de consultoria em viagens, enfatizando a importância do agente de viagens para poder competir com estes portais (GUIMARÃES; MENEZES, 2016).

Paralelamente ao impacto negativo nas agências de viagens, a internet é uma ferramenta de trabalho essencial neste setor, pois oferece ao agente novas oportunidades e ideias. Estas oportunidades podem ser determinantes na sobrevivência da empresa em um setor bastante competitivo e tecnológico (MARSILIO; VIANNA, 2015). Em 2001, Tomelin e Beli estudaram o reposicionamento do agente de viagens, apontando para a necessidade de um perfil menos provedor e mais administrador de informações junto aos clientes. 
Para a comercialização destes produtos e serviços, a empresa deve contar com o apoio de colaboradores capacitados e bem preparados, auxiliando e assessorando os clientes. São estas ações que podem facilitar o processo de compra.

Corrêa e Teixeira (2014) apontam que, ao analisar a demanda eas competências dos profissionais que atuam em agências de viagens, há carência de mão de obra qualificada para a ocupação de cargos operacionais e que os profissionais com maior dificuldade de contratação nas agências são os vendedores. Além da carência de profissionais qualificados, existe divergência de opiniões por parte dos gestores quanto ao grau de importância de determinadas competências para esses profissionais, uma vez que a atuação não é limitada pelo conhecimento teórico e empírico armazenado por determinada pessoa ao longo de sua vida. Faz-se necessária uma inteligência prática para lidar com determinadas tarefas e situações, um aglomerado de aprendizagens que pode ser construído ou descontruído, como: modelos mentais que são modificados ao longo do desenvolvimento pessoal. É importante destacar que alguns conhecimentos são construídos com base nas vivências e nas experiências individuais de cada pessoa, na interpretação e na forma como se apropria desta informação, sendo assim intransferível. Já o conhecimento teórico, a formação acadêmica e as especializações são conhecimentos que podem ser repassados, assimilados, apreendidos, testados e sua absorção pode ser comprovada (LUCKESI, 2008).

Os resultados do estudo de Cetin, Demircifti e Bilgihan (2016) sobre as competências necessárias para gestores que atuam na indústria do turismo sugerem que cursos de Turismo e Hotelaria deveriam oferecer disciplinas de recursos humanos, marketing, economia, estratégia, empreendedorismo e comportamento organizacional, a fim de promover a formação mais qualificada e ampliada. Nesta pesquisa, os gestores declararam que o conhecimento formal adquirido não foi suficiente para sua atuação e que os desafios enfrentados por gestores deste setor podem ser minimizados a partir da cooperação.

Diante deste contexto, a questão de pesquisa que originou este estudo é: quais as competências necessárias, sob a ótica do gestor, para os profissionais que trabalham na área de vendas de agências de viagens localizadas em Porto Alegre? 
A escolha por Porto Alegre se deu pelo número de agências disponíveis na cidade e, consequentemente, com um universo de respondentes considerável. Da mesma forma, a existência de dez instituições de nível superior que oferecem graduação de turismo na região metropolitana foi um ponto importante, uma vez que é preciso compreender o que o mercado está buscando neste profissional. O artigo busca contribuir com a discussão sobre o tema competências de profissionais atuantes na área de vendas das agências de viagens. Além disso, discute as vantagens e as desvantagens na contratação de determinados perfis profissionais.

O artigo está assim estruturado: no referencial teórico são abordados conceitos básicos de turismo e de agências de viagens e a importância das competências para o profissional que atua na área de vendas. O método detalha os procedimentos adotados para realização da pesquisa. Na apresentação e na análise dos dados são expostos os resultados decorrentes da pesquisa, e na discussão, são apresentadas as principais reflexões acerca dos resultados obtidos, relacionando-os às referências utilizadas. Finalmente, nas considerações finais são elencadas as principais conclusões geradas a partir do estudo, bem como as limitações da pesquisa e sugestões de novos trabalhos.

\section{O MERCADO DO TURISMO E O PROFISSIONAL DE VENDAS}

O turismo é uma atividade socioeconômica bastante abrangente e multidisciplinar. Para a Organização Mundial do Turismo - OMT (1994), o turismo é a atividade do viajante ao realizar visitas e estadas em lugares diferentes do seu entorno habitual, por um período superior às $24 \mathrm{~h}$ e inferior a um ano, com objetivo de lazer, negócios ou outras.

Neste mercado do turismo atuam as agências de viagens. Lohmann (2012) aponta que a agência de viagens é uma forma indireta de canal de distribuição, uma vez que funciona como um intermediário entre o potencial turista e os fornecedores. Para os turistas, as agências oferecem a facilidade de lhes proporcionar informações e dicas, recomendando o melhor produto que venha a satisfazer suas necessidades e desejos. Assim, entende-se que as 
agências de turismo podem ser prestadoras de serviços. Segundo Zeithaml e Bitner (2003), serviços são atos, processos e performances, como também todas as atividades econômicas cujo produto não é físico ou construído. $O$ serviço é consumido na hora em que é produzido e provê valor agregado (em formas como: conveniência, divertimento, economia de tempo, conforto ou saúde), que é essencialmente intangível e dedicado, primordialmente, a quem compra.

Para Denton (1999), os fornecedores de serviço com qualidade são decididamente empresas orientadas para as pessoas, ou seja, empresas que levam em consideração a qualidade subjetiva (exprime o conteúdo emocional) do serviço. Segundo este autor, essas empresas reconhecem que "serviços são pessoas" e, consequentemente, procuram tratar bem seus colaboradores, uma vez que estes são a ligação entre a organização e os clientes.

Em se tratando de agências de viagens, Schlüter e Winter (2003) afirmam que elas podem ser classificadas em três funções. A primeira é o canal de distribuição, que está relacionado à intermediação realizada pela empresa entre fornecedores (meios de hospedagem, serviços, transportes, etc.) e cliente final. Na segunda função, denominada viagem sob medida (forfait), são oferecidos serviços para grupos ou apenas uma pessoa, com a venda de pacotes turísticos alinhados à necessidade e ao desejo do cliente, de forma totalmente personalizada. Finalmente, a terceira função é a consultoria que consiste no fornecimento de informações aos clientes e aos potenciais turistas, auxiliando na decisão do destino, bem como nos produtos e serviços turísticos a serem adquiridos.

Independente da função que exercem, Lohmann (2012) classifica as agências de viagens em três grupos distintos: a) emissivas: quando enviam turistas para outros destinos; b) receptivas: quando recebem turistas em seu destino turístico, e c) mistas: quando realizam tanto atividades emissivas quanto receptivas.

Desta forma, entende-se que as agências operam de forma a facilitar a comunicação e o acesso do cliente com os fornecedores (transportes, meios de hospedagem, serviços, etc.), atuando como um facilitador. Por meio do conhecimento de seus colaboradores, é possível prestar uma consultoria auxiliando e direcionando o cliente na aquisição de produtos e/ou serviços 
alinhados à sua experiência, bem como fornecer informações e dicas para transformar a viagem em uma experiência agradável.

Castelli (1998) afirma que é necessário que as agências de viagem disponham, em seu quadro de colaboradores, de pessoas que tenham conhecimentos, habilidades e atitudes pertinentes, além de estarem suficientemente motivadas para realizar o seu trabalho. $O$ autor ressalta que a qualidade na prestação dos serviços das agências de viagem está atrelada à qualidade das pessoas que ali trabalham. Estes colaboradores podem ser especialistas e generalistas (SILVA, 2005). O empregado especialista é totalmente técnico, diferente do generalista, que além dos conhecimentos técnicos, possui outras habilidades importantes para a realização de atividades relacionadas à função. Além de diferenciar os tipos de colaboradores, Silva (2005) aponta que toda habilidade é uma competência.

Competência é o conjunto de conhecimentos, habilidades e atitudes que um profissional demonstra, podendo ser conhecida, também, pela sigla CHA - Conhecimento, Habilidade e Atitude (MCCLELLAND, 1973; MORELLHO; FROEHLICH, 2010). Sendo assim, a competência deve estar direcionada para as realizações que a pessoa ou equipe entrega. Trata da capacidade para aplicar habilidades, conhecimentos e atitudes em tarefas diárias e/ou operacionais. Pode-se dizer que competência é a mobilização de saber fazer, saber ser e saber agir, sendo assim definida como uma habilidade para alcançar um determinado propósito (DEPRESBITERIS, 2001).

Na contratação de novos colaboradores, é comum que estes apresentem qualificações genéricas. Assim sendo, a organização deve treinar novos colaboradores com o objetivo de capacitar a pessoa a exercer sua função. $O$ investimento em treinamento é recompensador para a empresa, pois além de desenvolver e/ou gerar novas habilidades, permite ao colaborador melhorar aquelas já existentes. A satisfação do colaborador não, necessariamente, melhora seu desempenho nas suas funções, mas afeta diretamente o seu comportamento, seja com os colegas, ou com relação à eficiência e à eficácia de seu trabalho (MORELLO; FROEHLICH, 2010). 
Atualmente, percebe-se a busca por profissionais em constante adaptação e com conhecimentos, relacionamentos e capacidade para desempenhar as atividades em sintonia com os objetivos da empresa. De acordo com Castelli (1998), o investimento na qualidade, tanto pessoal quanto processual, é essencial para uma empresa. Desta forma, ao investir em qualidade, obtêmse resultados positivos, como: menos defeitos, melhores produtos, bem-estar, menor absenteísmo, mais clientes satisfeitos e uma imagem melhor e mais positiva da empresa.

Percebe-se, então, que estudos sobre competências para o turismo ainda precisam ser realizados. Cetin, Demirciftci e Bilgihan (2016) apontaram esta necessidade ao analisarem conhecimentos, habilidades e atitudes necessários para a gestão efetiva de receitas na indústria hoteleira, indicando quatro grupos principais de competências: a) pessoais, b) genéricas, c) técnicas e d) éticas. É possível dizer que estes grupos estão mais relacionados à visão do indivíduo.

Zarifian (2001) apresenta uma visão mais voltada para a própria organização, classificando competências da seguinte forma: a) competências sobre processos, que se referem aos processos de trabalho; b) competências sobre a organização, relacionadas ao conhecimento do fluxo de trabalho; c) competências técnicas, que dizem respeito ao conhecimento específico sobre algo a ser realizado; d) competências de serviços, que alinham as competências técnicas ao resultado final gerado para o consumidor; e) competências sociais, aquelas relacionadas ao comportamento individual (comunicação, autonomia, etc.).

Bitencourt (2005) afirma que o desenvolvimento de competências contribui para a formação de pessoas, com relação à mudança de percepção e atitude no ambiente de trabalho e suas atividades. Com ênfase na formação, Boyatizis (1982) diz que competências são aspectos relacionados à natureza humana e que, em grande parte, podem determinar o resultado da organização. Da mesma forma, Spencer e Spencer (1993) relacionam competências com as características intrínsecas de uma pessoa, as quais servem de base para seu comportamento e desempenho na organização. Direcionado para a aptidão e valores, Boog (1991) afirma que competências são as qualidades de um indivíduo para resolver determinadas questões ou fazer alguma determinada 
atividade. Apesar dos autores divergirem em alguns aspectos, pode-se dizer que os conceitos enfatizam formação, resultados, aptidão e desempenho.

Percebe-se, então, que as competências profissionais possuem o objetivo de formar colaboradores qualificados para o setor, assegurando o cumprimento das tarefas e das obrigações profissionais de forma mais assertiva (AKATIEVA; BATALOVA; MERZLYAKOVA, 2015).

Para Starbuck (1992), o conhecimento tácito traz contribuição significativa ao negócio quando aplicado. Complementando este pensamento, Polanyi (1967) afirma que o conhecimento tácito é de caráter pessoal, de difícil formalização e transmissão, uma vez que decorre da experiência prática de cada indivíduo. Com o tempo, esse conhecimento pode se converter em conhecimento explícito, que se trata de formalizar o conhecimento e comunicá-lo em linguagem sistemática.

Com um posicionamento mais próximo ao desenvolvido por McClelland (1973), Deluiz (2001) afirma que o conceito tradicional de qualificação estava relacionado apenas aos componentes explícitos da qualificação do colaborador: educação escolar, formação técnica e experiência profissional. No plano educacional era relativo à escolaridade e aos diplomas; no mercado de trabalho, aos salários, aos cargos e às carreiras.

Silva (2005) afirma que algumas empresas modificaram seu sistema de contratação buscando pessoas multifuncionais e autônomas. Isso demonstra o quanto os profissionais de postura passiva e preocupados apenas em realizar as funções de seu cargo estão perdendo espaço no mercado de trabalho. O estudo de Akitieva et al. (2015) aponta para a ocorrência de dois grupos de competências para os bacharéis em turismo: a) genérica e b) profissional. As competências genéricas são reveladas não só na resolução de tarefas de especialistas, mas também em como as pessoas percebem, avaliam e compreendem o mundo além de suas atividades profissionais. Já as competências profissionais prosseguem os objetivos-chave do sistema de formação profissional, que é o objetivo da formação de pessoal qualificado para a indústria do turismo. É importante ressaltar que a empresa também possui o importante papel de auxiliar e facilitar o desenvolvimento dessas pessoas no ambiente de trabalho. 
Neri (1999) ressalta a importância de programas de treinamento em organizações que trabalham com sistemas de competência. Não se trata apenas do saber fazer, mas também é necessário entender o porquê algo é feito. Desenvolver competências é utilizar e potencializar a capacitação pelas vivências, realizando uma negociação entre pessoas e empresa sobre os resultados esperados. Este processo de treinamento tem como objetivo principal fazer com que as pessoas pensem e reelaborem os significados da contribuição de seus resultados para a organização, além de ensiná-las a fazer autocrítica. Treinar envolve também ensinar as pessoas a utilizarem técnicas e/ ou práticas interativas de conhecimento, com o objetivo de fazê-las refletir e se posicionarem diante das situações empresariais e pessoais.

De acordo com Ruas, Antonello e Boff (2005), a crescente utilização da noção de "competência" no ambiente empresarial brasileiro tem renovado o interesse sobre esse conceito. Sob uma perspectiva mais estratégica (competências organizacionais, competênciasessenciais), ou sob uma configuração mais específica de práticas associadas à gestão de pessoas (seleção, desenvolvimento, avaliação e remuneração por competências), a noção de competência tem aparecido como importante referência dentre os princípios e as práticas de gestão no Brasil.

Há uma maior relevância na construção da noção de competência atribuída principalmente pela crescente instabilidade da atividade econômica, pela baixa previsibilidade da relação das empresas com seus mercados e clientes, e pela intensificação das estratégias de customização. Esses elementos são mais visíveis no plano estratégico do que nos níveis tático e operacional, pois assumem novas formas de conceber e organizar o trabalho, mudando de uma disposição mais estável e previsível para outra bastante diferenciada e fluida. Esse cenário propicia que o processo tenha uma tendência a ser mais focado no objetivo do trabalho (seu resultado) do que na forma de como deve ser feito (processo). O setor de serviços é considerado a atividade econômica predominante no contexto atual de negócios, tendo seu foco cada vez mais dirigido para os resultados e para a responsabilidade do que para a tarefa.

Diante dos autores apresentados e buscando contemplar os diferentes aspectos apontados, esta pesquisa adota o mapa de competências, apresentado na Figura 1 como base para a coleta e análise dos dados. 
Figura 1 - Mapa das competências (CHA)

\begin{tabular}{|c|c|c|}
\hline$C$ & 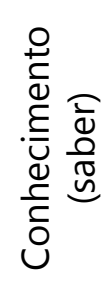 & $\begin{array}{l}\text { Conhecimentos necessários para atender ao perfil da função, os quais } \\
\text { são adquiridos por meio da educação continuada (cursos, programas de } \\
\text { capacitação, cursos de idiomas e informática e constante atualização por } \\
\text { meio de leituras, visitas técnicas, programas culturais, etc.). } \\
\text { Grau de instrução (requisito mínimo de acesso e desejável para a função). } \\
\text { Experiências profissionais. }\end{array}$ \\
\hline $\mathrm{H}$ & 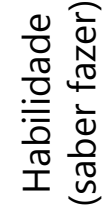 & Atividades da função que devem ser exercidas pelo profissional. \\
\hline A & 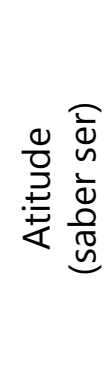 & $\begin{array}{l}\text { Comportamentos exigidos para o desempenho da função. } \\
\text { Exemplo: } \\
\text { Visão sistêmica: conhece o mercado de atuação da sua área de negócio; } \\
\text { realiza leitura de cenários internos e externos e visualiza tendências; } \\
\text { percebe a interação e a interdependência das partes que compõem o todo; } \\
\text { conhece todos os processos-chave da empresa; assume riscos calculados } \\
\text { na tomada de decisão conforme o seu escopo de atuação e nível de } \\
\text { autonomia decisória; avalia o impacto de suas decisões e resultados. }\end{array}$ \\
\hline
\end{tabular}

Fonte: Adaptada de Morello e Froehlich (2010)

MÉTODO

Este estudo tem uma abordagem quantitativa. O planejamento da pesquisa ocorreu em sete etapas: a) identificação do objetivo, b) organização e elaboração do referencial teórico, c) escolha do tipo de questionário, plataforma e meio de alcançar os respondentes, d) elaboração do questionário em si na plataforma escolhida, e) envio do link dos questionários, f) realização dos testes no SPSS a partir dos questionários recebidos e g) análise dos resultados.

INSTRUMENTO DE PESQUISA

Com o objetivo de detectar o nível de importância das competências que os gestores consideram quando necessitam contratar novos colaboradores, sendo que estas competências foram segmentadas com base McClelland (1973), ficando divididas em: conhecimentos, habilidades e atitudes. $\mathrm{O}$ instrumento foi composto por quatro blocos.

O primeiro bloco continha questões referentes à caracterização do respondente: 1) gênero do respondente (feminino ou masculino); 2) idade 
do respondente ${ }^{2}$ (18 a 36 anos, 37 a 56 anos, mais de 57 anos); 3) formação (primeiro grau incompleto, primeiro grau completo, segundo grau incompleto, segundo grau completo, superior incompleto, superior completo, pósgraduação); 4) tempo no qual trabalha na empresa (menos de 1 ano, 1 a 5 anos, 6 a 10 anos, mais de 10 anos); 5) cargo exercido (administrador, diretor/ gerente, outros).

No segundo bloco incluiu-se apenas uma questão referente à idade da empresa, uma vez que todos os respondentes atuam em agências de viagens e turismo (menos de 1 ano, 1 a 5 anos, 6 a 10 anos, mais de 10 anos). No terceiro bloco, o respondente avaliava cada competência por meio de uma escala do tipo Likert, de Discordância/Concordância, composta de cinco pontos. Os itens foram adaptados de instrumentos utilizados em pesquisas anteriores (CORRÊA; TEIXEIRA, 2014; REIS; GUTIERREZ, 2008). No quarto bloco, o respondente deveria ordenar as sugestões fornecidas de acordo com sua opinião sobre as principais dificuldades na contratação na área de vendas.

\section{AMOSTRA E COLETA DE DADOS}

Para identificar as agências de viagens existentes em Porto Alegre, foi realizada uma pesquisa no site da Cadastur ${ }^{3}$ em 11 de abril de 2016. Nesta pesquisa foram aplicados os seguintes filtros: a) prestadores (em operação), b) agências de turismo, c) UF Rio Grande do Sul, d) Localidade Porto Alegre, e) Não possuem frota própria, f) Serviços prestados: venda ou intermediação remunerada de seguros de viagem, passeios ou excursões e de cartões de assistência destinados a viajantes. Para estes filtros foram encontrados 180 resultados, sendo este o universo desta pesquisa.

Os filtros utilizados foram baseados em agências em funcionamento, dentro da cidade de Porto Alegre. O critério "sem frota própria" permitiu que fossem identificadas somente agências que prestam serviço de intermediação entre fornecedores de hotéis, passagens aéreas, fretamento rodoviário, seguro

2 A classificação dos grupos está relacionada às gerações Baby Boomer, $\mathrm{X}$ e $\mathrm{Y}$, conforme apresentado por Robbins (2005).

3 Sistema de cadastro de pessoas físicas e jurídicas que atuam na área do turismo, coordenado pelo Ministério do Turismo em parceria com os órgãos oficiais de turismo de cada Estado. 
viagem e demais produtos turísticos com o consumidor final, retirando do filtro "qualquer operadora de turismo".

A coleta de dados foi realizada por meio de questionário, cujo link https:// pucrs.qualtrics.com/jfe/form/SV_5is6AVt6XkKRNSB foi enviado para o endereço eletrônico de todas as agências, sendo recebidas 69 respostas entre o período de 25 de abril a 25 de julho. Entretanto, ao analisar os dados no software SPSS 17 , foram consideradas válidas somente 67 respostas. A exclusão de dois questionários ocorreu porque havia questões não respondidas. O percentual de questionários recebidos em relação à população é de 37,22\%.

\section{TRATAMENTO DOS DADOS}

Inicialmente, foi realizada a análise descritiva dos dados nominais coletados, indicando as frequências de cada característica respondida no primeiro e segundo blocos do instrumento de pesquisa. Para analisar os dados do terceiro bloco, foram utilizadas as técnicas estatísticas: a) análise fatorial, b) correlação, c) Teste T e d) ANOVA (BRUNI, 2011; FIELD, 2009; HAIR et al., 2005). Os dados do quarto bloco foram analisados a partir da análise descritiva e considerou-se a frequência de respostas em cada colocação (da $1^{a}$ à $6^{a}$ posição de preferência). Todos os testes foram realizados no SPSS 17.

Na técnica de análise fatorial exploratória (AFE), que tem como objetivo reduzir as variáveis a dimensões (HAIR et al., 2005; FIELD, 2009), foram extraídos os fatores a partir das variáveis que compõem o terceiro bloco do instrumento. Cada fator foi transformado em uma variável a partir da média das respostas do conjunto das variáveis que o compõem. Aplicou-se, então, a técnica de correlação para verificar a intensidade da relação entre dois fatores de cada vez.

Em seguida, foi realizado o Teste $T$ para verificar as diferenças nas médias obtidas em cada fator para homens e mulheres. Da mesma forma, utilizou-se a técnica ANOVA para verificar a diferença nas médias para cada fator conforme os seguintes critérios: a) idade do respondente, b) formação, c) tempo que trabalha na empresa, d) cargo, e) idade da empresa. 


\section{APRESENTAÇÃO E ANÁLISE DOS RESULTADOS}

A primeira análise realizada foi referente ao perfil dos respondentes. A Figura 2 apresenta os dados referentes ao perfil dos respondentes em forma de gráfico.

Figura 2 - Perfil dos Respondentes

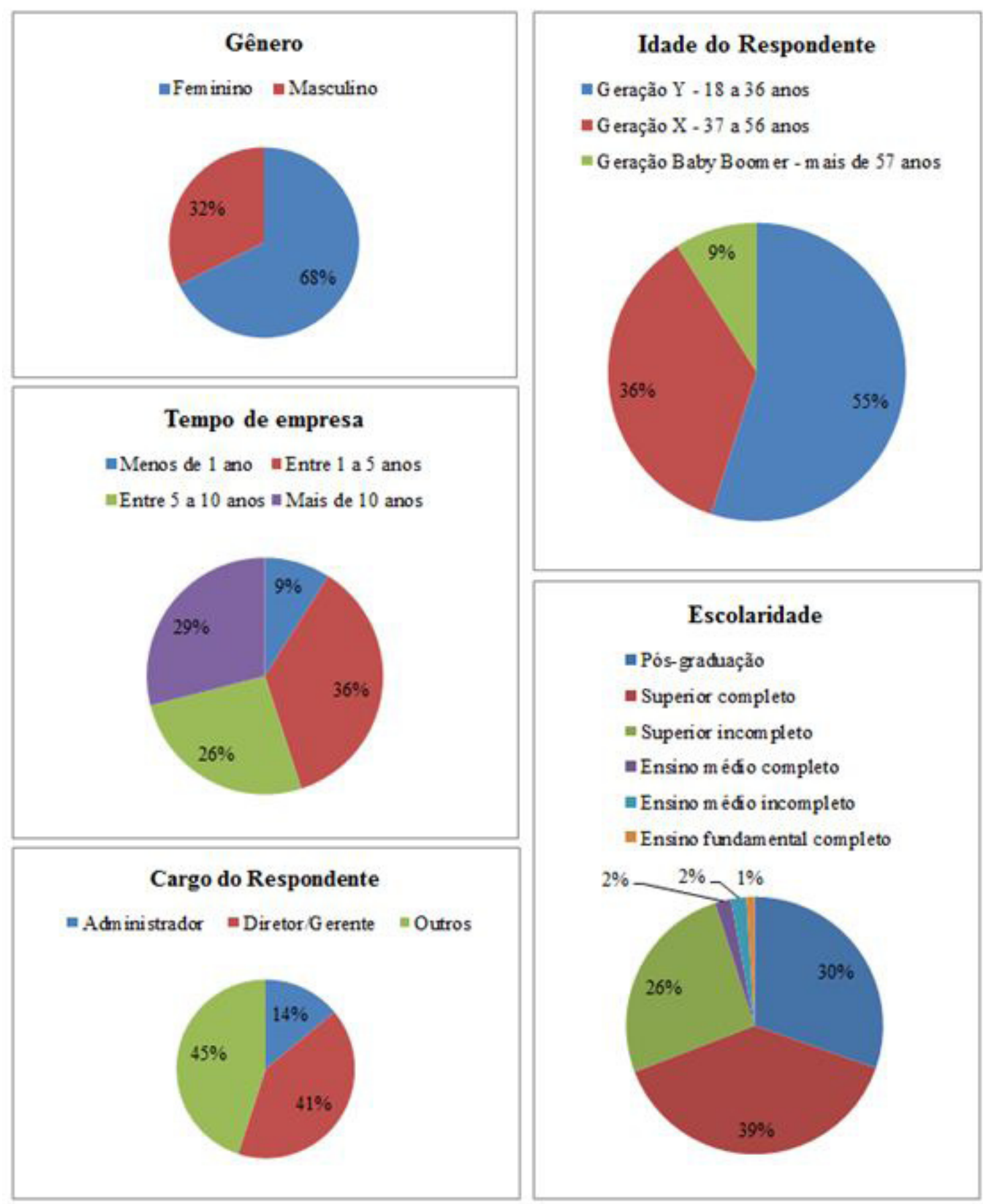

Fonte: dados da pesquisa (2016)

A amostra é formada por $68 \%$ dos respondentes do gênero feminino e $32 \%$ do gênero masculino. Com relação à idade, 55\% tinham de 18 a 36 anos; 36\%, de 37 a 56 anos; e 9\%, mais de 57 anos. Quanto à escolaridade, a maioria possui 
graduação (39\%) e/ou pós-graduação (30\%). Dentre aqueles que não possuem graduação, 26\% têm curso superior incompleto; $2 \%$, ensino médio completo; $2 \%$, ensino médio incompleto; e 1\%, ensino fundamental completo. Quanto ao tempo de empresa, 36\% estão na empresa de 1 a 5 anos; 29\% possuem mais de 10 anos de empresa; $26 \%$ dos respondentes estão de 5 a 10 anos na empresa; e a menos de 1 ano, somente $9 \%$. Em relação ao cargo dos respondentes, $45 \%$ assinalou o campo "outros", que caracteriza o coordenador de vendas e o sócio/proprietário; 41\% são diretores/gerentes, e 14\% são administradores. Quando questionados sobre a idade da empresa, as respostas foram que $54 \%$ tinham mais de 10 anos; 25\%, entre 6 e 10 anos; 20\%, entre 1 e 5 anos; e 1\%, menos de 1 ano de existência.

Após analisar o perfil dos respondentes, iniciou-se a análise multivariada dos dados, realizando a AFE, com rotação Varimax. Nos primeiros testes realizados, observou-se que o valor do teste $\mathrm{KMO}$ foi de 0,682, o que caracteriza a adequação dos dados. Além do KMO, o teste de Bartlett também foi adequado, com $p<0,000$ e $\chi^{2}=243,362$ com graus de liberdade = 91 (HAIR et al., 2005). Outro teste utilizado foi o Alpha de Cronbach, que mede a consistência ou a confiabilidade do instrumento. Este valor deve ser próximo a 1 (HAIR et al., 2005) e, no caso da amostra, foi 0,750. Ou seja, estes testes apontam que o instrumento é confiável, medindo aquilo que se propõe a medir. A estrutura inicial apresentada na análise extraiu cinco fatores com variância explicada de $66,62 \%$. Este percentual indica a capacidade de explicação dos cinco fatores em relação às competências exigidas do profissional que atua com vendas em agências de turismo. Entretanto, um dos fatores apresentava somente duas variáveis, o que não é indicado por Hair et al. (2005). Ressalta-se que a exclusão de cargas menores do que 0,5 foram utilizadas.

Com o objetivo de buscar a adequação das variáveis em três fatores - CHA (Conhecimento, Habilidade e Atitude), conforme indicado na revisão da literatura, foi realizado novo teste, estabelecendo-se a extração de três fatores. Da mesma forma, foi realizado o teste com a extração de 4 fatores. Entretanto, os resultados apontaram a exclusão de duas variáveis. A fim de manter todas as variáveis, a análise permaneceu com cinco fatores que foram assim nomeados: a) Habilidade; b) Qualificação técnica; c) Conhecimento tácito; d) Atitude; e e) Conectividade. 
O fator Habilidade foi formado pelas variáveis: a) facilidade na comunicação; b) habilidade em vendas; c) bom relacionamento com o cliente, e d) capacidade de entender as necessidades do cliente, ressaltando o foco no cliente. Em Qualificação Técnica ficaram alocadas as variáveis: a) conhecimento em turismo; b) conhecimento em outros idiomas; e c) formação superior, apontando para o conhecimento adquirido formalmente (LUCKESI, 2008). Para Conhecimento Tácito foram consideradas as variáveis: a) experiência pessoal em viagens; b) experiência na área; c) conhecimento operacional, o que indica a importância do conhecimento adquirido informalmente e a partir da vivência (STARBUCK, 1992). O fator Atitude foi formado pelas variáveis: a) pró-atividade e b) bom relacionamento interpessoal, reforçando a ideia de um comportamento ativo e que busque a cooperação (CETIN; DEMIRCIFTI; BILGIHAN, 2016). Finalmente, em Conectividade foram alocadas: a) facilidade de aprendizagem e b) conhecimento em informática, que está alinhado à necessidade atual apontada por Cetin, Demirciftçi e Bilgihan (2016). A distribuição das variáveis e das suas cargas fatoriais bem como o Alpha de Cronbach por fator foram expressas na Tabela 1.

Tabela 1 - Fatores extraídos e Cargas Fatoriais das Variáveis

\begin{tabular}{|c|c|c|c|c|c|}
\hline & \multicolumn{5}{|c|}{ Fatores } \\
\hline & Habilidade & $\begin{array}{l}\text { Qualificação } \\
\text { técnica }\end{array}$ & $\begin{array}{l}\text { Conhecimento } \\
\text { Tácito }\end{array}$ & Atitude & Conectividade \\
\hline $\begin{array}{l}\text { V11 - Facilidade na } \\
\text { comunicação }\end{array}$ & 0,779 & & & & \\
\hline V12 - Habilidade em vendas & 0,768 & & & & \\
\hline $\begin{array}{c}\text { V10 - Bom relacionamento com } \\
\text { clientes }\end{array}$ & 0,562 & & & & \\
\hline $\begin{array}{l}\text { V20 - Capacidade de entender } \\
\text { as necessidades do cliente }\end{array}$ & 0,526 & & & & \\
\hline $\begin{array}{c}\text { V16 - Conhecimento em } \\
\text { turismo }\end{array}$ & & 0,762 & & & \\
\hline $\begin{array}{l}\text { V13 - Conhecimento em outros } \\
\text { idiomas }\end{array}$ & & 0,744 & & & \\
\hline V17 - Formação superior & & 0,702 & & & \\
\hline $\begin{array}{c}\text { V19 - Experiência pessoal em } \\
\text { viagens }\end{array}$ & & & 0,846 & & \\
\hline V14 - Experiência na área & & & 0,671 & & \\
\hline V9 - Conhecimento operacional & & & 0,503 & & \\
\hline V21 - Pro-atividade & & & & 0,866 & \\
\hline $\begin{array}{l}\text { V22 - Bom relacionamento } \\
\text { interpessoal }\end{array}$ & & & & 0,568 & \\
\hline
\end{tabular}




\begin{tabular}{|c|c|c|c|c|c|}
$\begin{array}{c}\text { V18 - Facilidade de } \\
\text { aprendizagem } \\
\text { V15 - Conhecimento em } \\
\text { informática }\end{array}$ & & & & 0,853 \\
\hline Alpha de Cronbach por fator & 0,681 & 0,680 & 0,698 & 0,587 & 0,550 \\
\hline
\end{tabular}

Método de extração: Análise de componentes principais.

Método rodado: Varimax com normatização Kaiser.

Fonte: Dados da pesquisa (2016).

Após extrair e nomear os fatores, foi aplicado o teste Correlação de Pearson. Percebe-se que houve correlação moderada entre os fatores Qualificação Técnica e Conhecimento Tácito. Além disso, houve correlação leve entre os fatores: a) Habilidade e Conhecimento tácito, b) Habilidade e Atitude e c) Habilidade e Conectividade. Os índices utilizados para esta classificação são apontados por Hair (2005).

A correlação de maior intensidade foi observada entre os fatores Qualificação Técnica e Conhecimento Tácito. Uma possível explicação pode estar relacionada à possibilidade de geração de conhecimento tácito a partir da qualificação técnica, uma vez que o primeiro se caracteriza pela experimentação e pela aplicação dos conhecimentos adquiridos formalmente.

Já, os fatores Conhecimento Tácito, Atitude e Conectividade estão correlacionados de forma leve com o fator Habilidade. Uma explicação para a correlação entre Conhecimento Tácito e Habilidade é que quanto mais experiências vivenciadas, maior a possibilidade de desenvolver habilidades pessoais e profissionais. Damesma forma, as atitudes relacionadas à proatividade e ao bom relacionamento pessoal podem facilitar o desenvolvimento de habilidades necessárias ao profissional da área de vendas. Facilidade de aprendizagem e conhecimento em informática, variáveis que explicam a Conectividade, também favorecem o desenvolvimento de habilidades pessoais e profissionais. A Tabela 2 apresenta as correlações entre os fatores, destacando aquelas que foram significativas.

Tabela 2 - Correlação de Pearson

\begin{tabular}{|c|c|c|c|c|}
\cline { 2 - 4 } \multicolumn{1}{c|}{} & Habilidade & Qualificação Técnica & Conhecimento Tácito & Atitude \\
\hline Qualificação Técnica & 0,190 & & & \\
\hline Conhecimento Tácito & $\mathbf{0 , 2 8 8 ^ { * }}$ & $\mathbf{0 , 5 0 4}^{*}$ & & \\
\hline
\end{tabular}


ISSN: 1983-7151

\begin{tabular}{|c|c|c|c|c|}
\hline Atitude & $\mathbf{0 , 3 3 6 ^ { * * }}$ & $-0,046$ & $-0,024$ & \\
\hline Conectividade & $\mathbf{0 , 2 9 8}^{*}$ & 0,155 & 0,220 & 0,166 \\
\hline
\end{tabular}

*correlação significativa a 0,05

${ }^{* *}$ correlação significativa a 0,01

Fonte: Dados da pesquisa (2016).

A Tabela 3 apresenta a análise do quarto bloco do questionário, cujos respondentes deveriam ordenar as dificuldades propostas de acordo com sua opinião. Ao serem analisadas as respostas, percebeu-se que a dificuldade Falta de Conhecimento em Turismo foi considerada a principal. A Dificuldade na Comunicação foi mais citada como a segunda principal e a Falta de Iniciativa ficou em terceiro lugar. Os demais itens não foram considerados tão relevantes pelos gestores. Por outro lado, é importante destacar que a dificuldade "falta de disposição para aprender" teve uma frequência alta de indicações.

Tabela 3 - Estatística descritiva: frequência das dificuldades apontadas pelos gestores

\begin{tabular}{|c|c|c|c|c|c|c|}
\hline Dificuldade & \multicolumn{5}{|c|}{ Ordem } \\
\cline { 2 - 7 } & 10 & $2^{\circ}$ & $3^{\circ}$ & $4^{\circ}$ & $5^{\circ}$ & $6^{\circ}$ \\
\hline 1- Falta de conhecimento em turismo & $\mathbf{2 0}$ & 11 & 5 & 12 & 9 & 7 \\
2- Dificuldade na comunicação & 7 & $\mathbf{2 1}$ & 18 & 7 & 10 & 1 \\
3- Falta de iniciativa & 12 & 17 & $\mathbf{2 4}$ & 6 & 5 & 0 \\
4- Falta de conhecimento em informática & 1 & 0 & 2 & 15 & 13 & 33 \\
5- Desconhecimento de técnicas de venda & 9 & 5 & 7 & 12 & 20 & 11 \\
6- Falta de disposição para aprender & 15 & 10 & 8 & 12 & 7 & 12 \\
\hline
\end{tabular}

Fonte: Dados da pesquisa (2016).

$\mathrm{Na}$ aplicação da Anova, a única característica a apresentar resultados significativos foi Formação. A diferença de média foi significativa comparando os respondentes com: pós-graduação, superior completo e superior incompleto (os demais grupos não foram considerados, pois havia apenas um representante em cada um deles). Os grupos com formação superior completo (média = 3,96 ) e pós-graduação (média $=4,03$ ) tem média estatisticamente maior que a superior incompleta (média $=3,61$ ).

Este teste traduz que gestores e administradores com formação mais elevada consideram este um fator importante na análise de candidatos para o setor de vendas. O Teste T não apresentou diferença de média significativa. 
O estudo buscou compreender as competências necessárias ao agente de vendas que atua em agências de viagem. Desta forma, foi utilizado o mapa de competências adaptado de Morello e Froehlich (2010), abordando a relevância de três fatores: Conhecimento (Qualificação Técnica), Habilidade e Atitude. No entanto, ao aplicar a pesquisa e analisar os dados, foram encontrados dois fatores além dos iniciais, que foram classificados como: Conhecimento Tácito e Conectividade. Estes resultados reforçam que o agente de vendas precisa aplicar o conhecimento adquirido informalmente e a partir das experiências vivenciadas (STARBUCK, 1992). Da mesma forma, a Conectividade é um fator importante, uma vez que Cetin, Demirciftçi e Bilgihan (2016) identificaram para a característica do agente de viagens ser o profissional responsável por selecionar as informações importantes para os clientes.

Para Abreu (2015), não é possível separar competência da ação, considerando que a competência se refere aos recursos pessoais utilizados para realização de uma determinada função ou atividade. O gestor, ao tomar a decisão sobre a contratação de um colaborador, depara-se com a situação de que conhecimentos, capacidades e aptidões relativas ao cargo somente podem ser avaliados e percebidos durante uma ação, seja ela real ou simulada.

O desenvolvimento de competências contribui para a formação de pessoas, com relação à mudança de percepção e de atitude no ambiente de trabalho (BITENCOURT, 2005). A formação de cada pessoa é baseada em seu grau de estudo, mas também nas suas vivências pessoais, tornando cada profissional único. Nas organizações diz-se que uma função pode ser desempenhada por qualquer profissional, porém o que diferencia é o fato de cada pessoa possuir maneiras diferentes de realizar determinada ação, além de habilidades e atitudes que são inatas a cada indivíduo.

Os resultados do bloco relacionado à ordenação das principais dificuldades apontam a importância do conhecimento em turismo e para o relacional (comunicação) fundamentalmente. Tanto o desconhecimento de técnicas de vendas quanto a falta de conhecimento em informática não são considerados 
dificuldades importantes, talvez porque os gestores percebam que estas técnicas podem ser ensinadas. A indicação da dificuldade "falta de disposição para aprender" corrobora com os resultados do estudo de Cetin, Demirciftçi e Bilgihan (2016). Eles apontam que alguns obstáculos podem ser minimizados a partir do estímulo à colaboração, em vez da competição. Talvez este seja um aspecto importante a ser levado em consideração: a interação entre os agentes de viagem, possibilitando o compartilhamento de experiências e conhecimentos, bem como o desenvolvimento da habilidade relacionada ao aspecto relacional.

\section{CONSIDERAÇÕES FINAIS}

O presente artigo tinha como objetivo compreender as competências necessárias, sob a ótica do gestor, para os profissionais que trabalham na área de vendas de agências de viagens localizadas em Porto Alegre, baseado no cenário atual percebido, em que grande parte dos profissionais de vendas nas agências de viagens é oriunda de outras áreas. A função de um agente de viagens pode ser aprendida e executada por profissionais de outras áreas, diferente, por exemplo, do que ocorre no setor da saúde, que exige uma qualificação mais específica. Em virtude dessa facilidade de aprendizagem das funções do agente de viagens, justifica-se, portanto, uma maior diversificação dentro do setor.

A partir dos resultados, percebeu-se que, além de Conhecimento, Habilidades e Atitudes apontados como elementos importantes que formam uma competência, há outros aspectos que implicam a atuação do profissional de vendas: o conhecimento tácito e a conectividade. Além disso, pode-se dizer que a Qualificação Técnica não supera, em importância, as Habilidades dos profissionais de vendas. Esta constatação permite aos gestores uma maior amplitude e abertura no processo de seleção e contratação, pois derruba a ideia de que a empresa precisa somente de profissionais graduados na área de turismo e hotelaria. Pode-se afirmar, ainda, que baseado nos resultados deste estudo, possuir ou não formação acadêmica deixa de ser fator decisivo na contratação. Nesta linha, a correlação entre os fatores identificados pode 
indicar que quanto mais conhecimento tácito adquirido a partir das experiências, maior o desenvolvimento de qualificações técnicas.

A principal dificuldade identificada foi a falta de adesão dos gestores da área de agências de viagens em responder os questionários, fazendo com que, além do envio por e-mail, se fizesse necessário em alguns casos o reforço telefônico solicitando a participação.

Estes resultados poderão ser utilizados em estudos futuros que comprovem de forma mais abrangente este novo modelo de contratação na área de vendas, verificando a veracidade destas informações a nível regional, estadual e até mesmo nacional.

\section{REFERÊNCIAS BIBLIOGRÁFICAS}

ABREU, Carina Vasconcellos. O desenvolvimento de competências na formação de guia de turismo a partir da percepção de profissionais formados no Rio Grande do Sul. Revista Turismo: estudos e práticas, v. 4, n. 1, 2015.

AKATIEVA, Larisa; BATALOVA, Larisa; MERZLYAKOVA, Tatiana Okonnikova. Developing Graduate Competency Model for Bachelors of Tourism. Procedia-Social and Behavioral Sciences, v. 214, p. 375-384, 2015.

BITENCOURT, Claudia Cristina. Gestão de Competências e Aprendizagem nas Organizações. São Leopoldo: Unisinos, 2005.

BOOG, G. O desafio da competência. São Paulo: Best Seller, 1991.

BOYATIZIS, R. The Competence Manager: A Model Of Efective Performance. New York: Wiley, 1982.

BRUNI, A. L. PASW Aplicado à Pesquisa Acadêmica. São Paulo: Atlas, 2011.

CASTELLI, G. Excelência em Hotelaria: Uma Abordagem Prática. Rio de Janeiro: Qualitimark, 1998.

CETIN, Gurel; DEMIRCIFTÇI, Tevfik; BILGIHAN, Anil. Meeting revenue management challenges: Knowledge, skills and abilities. International Journal of Hospitality Management, v. 57, p. 132-142, 2016.

CORNER, Dolores Martin. Introdução ao Turismo. São Paulo: Roca, 2001. 
CORRÊA, Juliana Maria Ferreira Gomes; TEIXEIRA, Rivanda Meira. Demanda e Competências dos Profissionais: estudo em agências de viagens e hotéis em Aracaju, Sergipe. Revista Turismo em Análise, v. 25, n. 2, p. 422, 2014.

DELUIZ, Neise. Qualificação, competências e certificação: visão do mundo do trabalho. Formação, Brasília, v. 1, n. 2, p. 5-15, 2001.

DENTON, D. K. Qualidade em serviços: o atendimento ao cliente como vantagem competitiva. São Paulo: Makron Books, 1999.

DEPRESBITERIS, Léa. Certificação de competências: a necessidade de avançar numa perspectiva formativa. Formação, Brasília, v. 1, n. 2, p. 27-38, 2001.

FIELD, A. Descobrindo a estatística usando SPSS. Porto Alegre: Artmed, 2009.

GUIMARÃES, Marize das Grassas; MENEZES, Vanessa de Oliveira. $\mathbf{O}$ mercado de viagens no brasil e a influência da internet: as agências tradicionais e agências online. Revista: Turydes Revista Turismo y Desarrollo. ISSN, v. 2016, n. 20.

HAIR JR., J. F.; BABIN, B.; MONEY, A. H.; SAMOUEL, P. Fundamentos de Métodos de Pesquisa em Administração. Porto Alegre: Bookman, 2005.

LOHMANN, Guilherme. Teoria do turismo: conceitos, modelos e sistemas. São Paulo: Aleph, 2012.

LUCKESI, Cipriano Carlos. Avaliação da aprendizagem escolar. São Paulo: Cortez Editora, 2008, $19^{a}$ edição.

MARSILIO, Maguil; VIANNA, Silvio Luiz Gonçalves. Agências de Viagens e Turismo e o impacto da internet: um estudo bibliométrico. Turismo - Visão e Ação, v. 16, n. 2, p. 450476, 2015.

MCCLELLAND, David C. Testing for competence rather than for "intelligence". American psychologist, v. 28, n. 1, p. 1, 1973.

MORELLO, I. N.; FROEHLICH, C. Perfil e grau de satisfação dos trabalhadores das equipes de saúde da família de Estância Velha - RS. Gestão e Desenvolvimento, v. 7, p. 101 - 113, 2010.

NERI, Agnaldo. Gestão de RH por Competências e a Empregabilidade. Campinas, São Paulo: Papirus, 1999.

Organização Mundial do Turismo - OMT. Disponível em http://www.worldtourism.org

POLANYI, Michael. The tacit dimension. Knowledge in organizations. New York: Anchor Day Books, 1967. 
REIS, Grazielle Fraga; GUTIERREZ, Alejandro. Desenvolvimento de competências multifuncionais na hotelaria. CEP, v. 29055, p. 420, 2008.

ROBBINS, Stephen P. Percepção e tomada de decisões individual. Comportamento organizacional. São Paulo: Pearson Prentice Hall, p. 110-111, 2005.

RUANO, Alessandra. Gestão por Competências: Uma Perspectiva para Consolidação da Gestão Estratégica de Recursos Humanos. Rio de Janeiro: Qualitymark, 2003.

RUAS, Roberto; ANTONELLO, Claudia Simone; BOFF, Luiz Henrique. Os novos horizontes de gestão: aprendizagem organizacional e competências. Porto Alegre: Bookman Editora, 2005.

SANDBERG, J. Human Competence at Work. Suécia: Grafikerna I Kungalv AB, 1996.

SCHLÜTER, Regina G.; WINTER, Gabriel. Turismo: Una perspectiva empresarial. Buenos Aires: Centro de Investigaciones y Estudios Turísticos, 2003.

SILVA, Mateus de Oliveira. Gestão de Pessoas Através do Sistema de Competências: Estratégias, Processos, Desempenho e Remuneração: Fundamentos e Aplicação. Rio de Janeiro: Qualitymark, 2005.

SPENCER, L; SPENCER, S. Competence at Work. New York: John Wiley \& Sons, 1993.

STARBUCK, William H. Learning by knowledge-intensive firms. Journal of management Studies, v. 29, n. 6, p. 713-740, 1992.

TOMELIN, Carlos Alberto; BENI, Mario Carlos. Reposicionamento dos Serviços do Agente de Viagens diante das Tendências do Mercado e Visão Catarinense. Turismo-Visão e Ação, v. 4, n. 8, p. 119-120, 2001.

ZARIFIAN, Philippe. Objetivo Competências: Por uma Nova Lógica. Tradução de Maria C. V. Trylinki. Atlas: São Paulo, 2001.

ZEITHAML, V. A; BITNER, M. J. Marketing de Serviços: A Empresa com Foco no Cliente. Porto Alegre: Bookman, 2003.

\section{CONTRIBUIÇÃO DOS AUTORES NA CONSTRUÇÃO DO ARTIGO}

SANTOS: Elaboração do artigo; coleta e análise dos dados.

SANTOS: Orientação do trabalho; acompanhamento da elaboração de todas as etapas da pesquisa; análise dos dados. 